Review Article

\title{
Evidence based literature review of clinical management of non-alcoholic fatty liver disease in real world settings
}

\author{
Gourdas Choudhuri*, Varun Gupta
}

Department of Gastroenterology and Hepatobiliary Sciences, Fortis Memorial Research Institute, Gurgaon, Haryana, India

Received: 23 March 2017 Accepted: 21 April 2017

*Correspondence to:

Dr. Gourdas Choudhuri,

Email:

choudhuri.gour@gmail.com

Copyright: (C) the author(s), publisher and licensee Medip Academy. This is an openaccess article distributed under the terms of the Creative Commons Attribution NonCommercial License, which permits unrestricted noncommercial use, distribution, and reproduction in any medium, provided the original work is properly cited.

\begin{abstract}
The aim of the present review is to understand the gap between real world clinical practices, guidelines recommendations and to propose minimum essentials that can be followed in clinical practice in NAFLD patients in India. A detailed literature search of published medical reports in English language was performed on electronic databases such as PubMed and Cochrane, from 2000 to 2016 using relevant search terms. The search yielded 25 relevant articles whose full texts were retrieved and evaluated. Non-alcoholic fatty liver disease (NAFLD) is an emerging cause of liver disease in India. It is observed that physicians under appreciate the overlap between NAFLD and metabolic risk factors, thus missing a significant proportion of high-risk NAFLD patients. Lifestyle intervention is generally considered the first line therapy for patients with NAFLD without steatohepatitis while pharmacotherapy (in addition to lifestyle intervention) is suggested for patients with non-alcoholic steatohepatitis (NASH). Current therapies are directed towards improving the metabolic parameters which contribute to disease pathogenesis. Pharmacological therapies for NAFLD and NASH include antioxidants such as vitamin $\mathrm{E}$ and ursodeoxycholic acid; insulin sensitizers such as metformin and thiazolidinones, weight loss drugs like orlistat and consideration of bariatric surgery for morbidly obese patients. High degree of suspicion is necessary for diagnosing NAFLD in patients with metabolic risk factors. Further studies are required from India as genotype/clinico-pathological profile of Indian NAFLD patients differ from the western population. Further, prospective studies will fill the various missing links associated with management of NAFLD in Indian patients in a more effective manner.
\end{abstract}

Keywords: Non-alcoholic fatty liver disease, Non-alcoholic steatohepatitis, Ursodeoxycholic acid

\section{INTRODUCTION}

Nonalcoholic fatty liver disease (NAFLD) is emerging as an important cause of liver disease in India. ${ }^{1}$ The prevalence of NAFLD in Indian population is reported to be between $9-32 \%$ which is almost comparable to the Western countries. Approximately one quarter of the patients with NAFLD progress to non-alcoholic steatohepatitis (NASH) and as per a retrospective study, $41 \%$ of patients with NASH progress to liver fibrosis and $5.4 \%$ to end-stage liver disease. ${ }^{2}$ NAFLD, the hepatic counterpart of the metabolic syndrome, is a pathologic condition characterized by more than $5 \%$ lipid deposition in hepatocytes. ${ }^{3}$ It is a broader term that includes patients with simple steatosis and NASH that may progress to cirrhosis of the liver and hepatocellular carcinoma (HCC) ${ }^{4,5}$ NASH is an intermediate stage of liver damage which is histologically similar to alcoholic hepatitis in the absence of significant alcohol intake, (<20 grams/day for men and $<10$ grams/day for women) ${ }^{6}$

Most commonly associated risk factors for NAFLD include age above 40 years, male gender, central obesity, BMI $>25 \mathrm{~kg} / \mathrm{m}^{2}$, elevated fasting blood sugar, and high serum aspartate transaminase (AST) and alanine transaminase (ALT) levels. ${ }^{1}$ Furthermore, the prevalence of NASH is found to increase with the rising rate of obesity and type 2 diabetes mellitus (T2DM) in patients. ${ }^{1}$ 
Studies from the Western countries have reported the prevalence of NAFLD in general population to be 10 $24 \%$ and $57-74 \%$ for obese population. The corresponding rates for $\mathrm{NASH}$ in general and obese population were $3-4 \%$ and $15-20 \%$ respectively., Although NAFLD is more common in patients with obesity and T2DM, it does occur in lean and non-diabetic individuals as well. ${ }^{9-11}$ Compared to the Western countries, Indians are known to develop NAFLD at a lower degree of adiposity. ${ }^{9,12,13}$ In a recent populationbased epidemiologic study in India, $75 \%$ of individuals with NAFLD were found to be non-obese and $54 \%$ were neither overweight nor had central obesity. This is supported by findings from another recent study where it was observed that lean, non-alcoholic, non-diabetic, nonsmoking ethnic Asian Indians in comparison to matched Caucasians, Hispanics, Black and Eastern Asians had 2to 3-fold increase in insulin resistance and 2-fold increase in hepatic triglyceride content. ${ }^{13}$ Also, due to urbanization and its associated changes such as sedentary life and fat rich diet, Indians are becoming more prone to metabolic syndrome and its manifestation like NAFLD. ${ }^{14}$ There are a few well published guidelines that have been developed by the European Association for the Study of the Liver (EASL) and American Association for the Study of Liver Diseases (AASLD) for the management of NAFLD. However, it is observed that specialists other than Hepatologists under appreciate the overlap between NAFLD and metabolic risk factors, thus missing a significant proportion of high-risk NAFLD patients. ${ }^{15}$ Multiple NAFLD guidelines further increase the ambiguity on how to manage NAFLD in Indian settings. Therefore, the objective of the present review is to understand the gap between real world clinical practices, guidelines recommendations and to propose minimum essentials that can be followed in clinical practice in India.

\section{METHODS}

To meet the above stated objective, a literature search was performed using electronic databases such as Pubmed / Medline to identify relevant articles using relevant search terms. Criteria for search included publications on pathophysiology of NAFLD/NASH, their prevalence, diagnosis, etiology and treatment patterns from the year 2000 to 2016 in English language and limited to clinical human data. The search yielded 25 relevant articles whose full texts were retrieved and evaluated. An overall summary of these articles which included clinical practice guidelines, systematic reviews, meta-analysis, and review articles was developed for each section. Case reports and case series were not included in the review. All articles considered were published in the scientific literature.

\section{PATHOPHYSIOLOGY}

Pathogenesis of NASH is considered a two hit process which involves the accumulation of fat as the first hit and the hepatocellular injury in the fatty liver as the second hit. ${ }^{16}$ The first hit of steatosis occurs because of the imbalance between the fatty acid uptake, its oxidation, esterification and export as very low-density lipoprotein (VLDL) from the hepatocyte. Insulin resistance is thought to be the key factor which leads to increase in lipolysis and increased uptake of fatty acids by hepatocytes. ${ }^{8,17-20}$ The increased load of fatty acids in the hepatocytes increases the mitochondrial beta oxidation, leading to increase in reactive oxygen species. The increased mitochondrial oxidative stress leads to the second hit from steatosis to steatohepatitis and fibrosis by three mechanisms, namely lipid peroxidation, cytokine induction and Fas ligand induction. ${ }^{17,18,21}$ There is also three-hit and multiple-hit theory given for the pathogenesis of NAFLD. In three-hit hypothesis, a third hit has been proposed as the inadequate hepatocyte regeneration and apoptosis. In multiple-hit hypothesis it is suggested that multiple events such as lipotoxicity, increased oxidative stress, mitochondrial dysfunction, iron overload, and proinflammatory cytokines acts in parallel, that lead to NASH. ${ }^{22}$

\section{DIAGNOSIS}

Early and accurate detection of NAFLD is necessary for silent but potentially progressive nature of this disease. Diagnostic practices mainly include clinical, biochemical and radiographic tests. The diagnosis of NAFLD requires the following criteria to be met:

- There is hepatic steatosis by imaging or histology,

- There is no significant alcohol consumption,

- There are no competing etiologies for hepatic steatosis,

- There are no co-existing causes for chronic liver disease. $^{23}$

An algorithm is provided in Figure 1 for diagnosis and management of NAFLD patients in India. As per the guidelines given by Singh SP, EASL 2016 guidelines on NAFLD and Indian position paper on NAFLD, NAFLD patients should be assessed as follows. ${ }^{23-25}$

\section{Initial assessment}

It has been shown in several studies that there is a relatively poor knowledge among general physicians (GP) about NAFLD diagnosis and assessment. It has been observed that in real world clinical practice, important aspects of NAFLD such as BMI calculation, alcohol consumption and ultrasonography (US) are missed many a times. This is supported by a Loguercio's retrospective analysis of $104 \mathrm{GPs}$, in which alcohol consumption, BMI calculation, transaminases, and US was assessed only in minority of patients with liver steatosis. $^{26}$ 


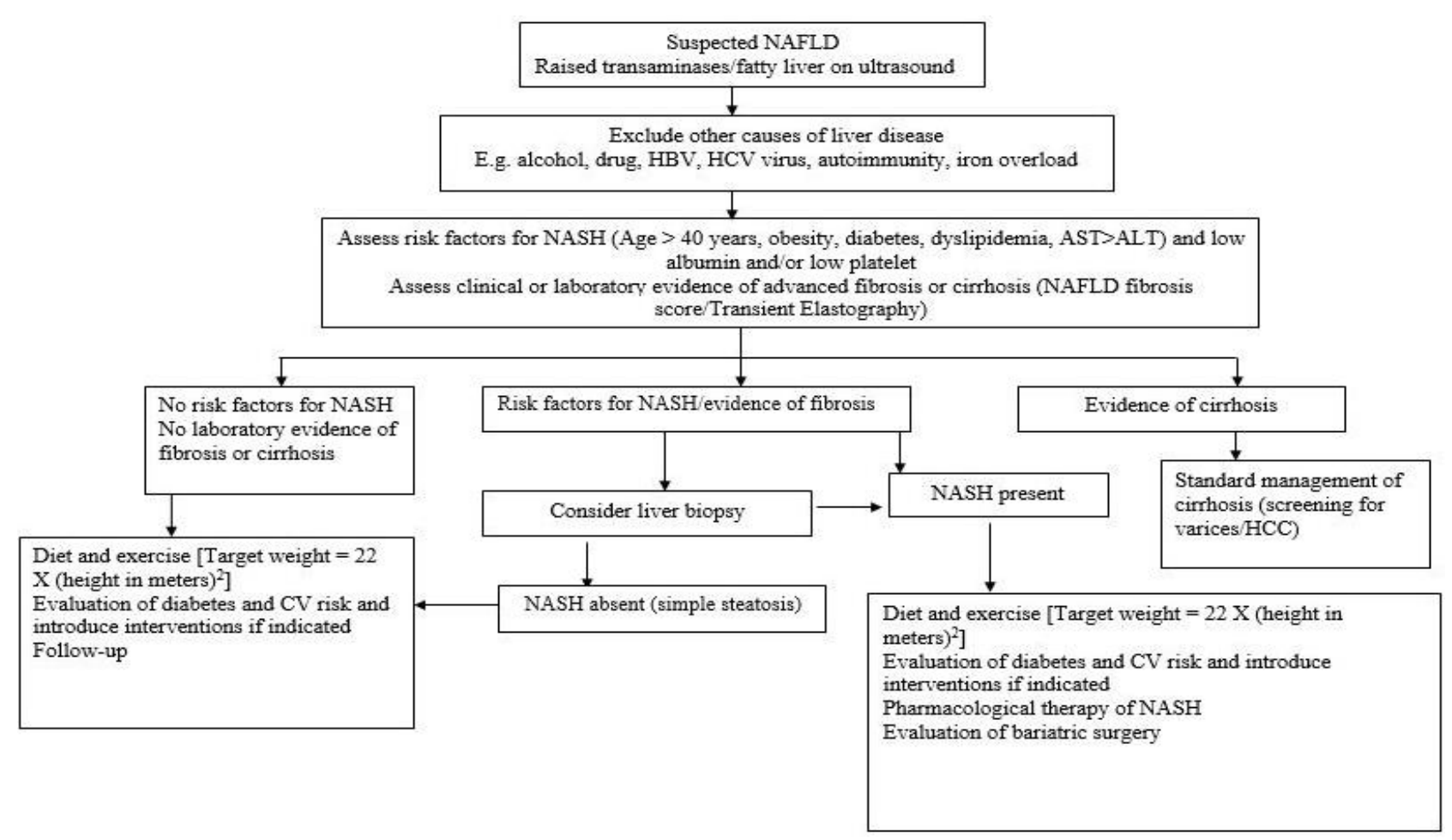

Figure 1: Management algorithm for NAFLD in indians.

\section{Medical history}

To begin with, a careful medical history should be taken of the patient especially for the exclusion of alcohol consumption to rule out alcoholic liver disease. ${ }^{23}$ For Asia-Pacific countries, the threshold intake of alcohol decided for men is 20 grams/day and 10 grams/day for women to diagnose as non-alcoholic liver disease. ${ }^{6}$ Patients with age $>50$ years, metabolic disorders such as obesity and diabetes mellitus are considered as high risk NAFLD patients. ${ }^{24}$

\section{Anthropometric evaluation}

Anthropometric evaluation must be done in all NAFLD patients in which height, weight, BMI and waist circumference is measured. The patients should be classified as overweight (BMI $\geq 23$ and $\leq 25 \mathrm{~kg} / \mathrm{m}^{2}$ ) or obese $\left(\mathrm{BMI}>25 \mathrm{~kg} / \mathrm{m}^{2}\right.$ ) according to Asia-Pacific criteria for obesity. Central obesity is diagnosed when waist circumference is $>90 \mathrm{~cm}$ for men and $>80 \mathrm{~cm}$ for women. ${ }^{27,28}$ Also, a measure of high blood pressure (BP $>130 / 85$ ) and insulin sensitivity (Using HOMA-IR index) is important as it is a criterion for metabolic syndrome and its presence has been linked to presence of fibrosis in the NAFLD patients. ${ }^{23}$

\section{Non-invasive assessment}

Non-invasive assessment involves blood tests and imaging. NAFLD is the most common cause of unexplained elevated liver transaminases, however this fact is ignored by many physicians. Patients with raised liver enzymes and metabolic risk factors such as diabetes should be screened for NAFLD using US and raised transaminases level, which is not practiced in real clinical practice. This is supported by Grattagliano's survey where $70 \%$ GPs underestimated the prevalence of NAFLD among general population, only $36.6 \%$ diabetic patients were screened for NAFLD and substantial subset of hypertransaminasemic patients were not even considered for NAFLD even in the presence of a metabolic risk factor. ${ }^{29}$

\section{Blood tests}

Blood test must include biochemical tests, hematological tests and immunological tests. Biochemical tests include serum bilirubin, AST, ALT, Gamma-glutamyl transferase (GGT), albumin, globulin, fasting sugar and fasting lipid profile. Hematological tests include complete blood count including total platelet count. A low platelet count favors significant fibrosis or cirrhosis. Anti-HCV antibodies and HBsAg should be excluded before diagnosis of NAFLD. Glycemic profile and insulin sensitivity should include fasting blood glucose, $75 \mathrm{~g}$ oral glucose tolerance test and fasting serum insulin. ${ }^{23}$

\section{Imaging}

Ultrasound being safe, inexpensive and widely available is a first-line imaging procedure for screening NAFLD. ${ }^{15}$ 
But it has serious limitations such as sensitivity is very low when steatosis is below $30 \%$ and unable to differentiate between simple steatosis and steatohepatitis. ${ }^{30-32}$ Non contrast- enhanced computerized tomography (CT) is an accurate $\mathrm{CT}$ technique to detect and characterize hepatic steatosis. ${ }^{33}$ Magnetic resonance imaging (MRI) also provides a sensitive and quantitative method to accurately assess hepatic steatosis as low as $3 \% .{ }^{34}$ If significant fibrosis cannot be ruled out, patients should be referred to a liver clinic for transient elastography (TE). Fibroscan is the most frequently used device for TE. It is a noninvasive method of assessing liver fibrosis that can be performed at the bedside or in the outpatient clinic. $^{35}$ As per EASL 2016 practice guidelines, monitoring of fibrosis progression may rely on a combination of biomarkers/scores and TE, although this strategy requires validation. ${ }^{13}$

\section{Serum fibrosis markers}

Given the invasive nature of LB, it was found in a survey that $90 \%$ physician in clinical practice use fibrosis markers to stage fibrosis. ${ }^{36}$ As clinical or biochemical markers alone are not sufficient to accurately predict the presence of NASH, multiple parameters have been combined into mathematical models to produce diagnostics algorithms to facilitate non-invasive assessment of NAFLD and its different stages. Some of such fibrosis markers are BARD score, FIB-4 test, Fibrometer, NFS and Fibrotest. ${ }^{37}$

\section{Liver biopsy}

Liver biopsy should be considered in patients with NAFLD who are at increased risk to have steatohepatitis and advanced fibrosis. Liver biopsy should be considered in patients with suspected NAFLD in whom competing etiologies for hepatic steatosis and co-existing chronic liver diseases cannot be excluded without a liver biopsy. ${ }^{38}$ A study by Ratziu showed that two thirds of HepatoGastroenterologists considered staging of fibrosis important for better prognosis. According to an Australian survey, 98\% non-liver specialist were able to correctly identify NASH on the basis of LB, while according to study by Ratziu, 38\% HepatoGatsroenterologist would not perform this procedure to estimate hepatic inflammation due to its invasive nature. ${ }^{36,39} \mathrm{LB}$ is still considered the gold standard for the prognosis by majority of physicians. LB is the only means to differentiate NASH from simple steatosis. Grading and staging of histology is done taking into consideration the degree of steatosis, lobular inflammation, ballooning degeneration and fibrosis. ${ }^{23}$

\section{MANAGEMENT OF NAFLD PATIENTS}

The management of patients with NAFLD consists of treating liver diseases as well as the associated metabolic disorders such as obesity, hyperlipidemia, insulin resistance and T2DM. Lifestyle intervention is generally considered the first line therapy for patients with NAFLD without steatohepatitis while pharmacotherapy (in addition to lifestyle intervention) is suggested to be used for patients with NASH (specially with significant fibrosis i.e. $\geq$ F2). ${ }^{3}$ As per EASL 2016 NAFLD guidelines, patients with diabetes, MetS, persistently increased ALT, high necroinflammation even with less severe disease could also be considered for pharmacotherapy to prevent disease progression. ${ }^{24}$

\section{LIFESTYLE MODIFICATION}

NAFLD is related to unhealthy lifestyle and requires lifestyle modifications such as weight loss and increased physical activity. ${ }^{1,40}$ According to few studies, lifestyle modification improves aminotransferases and hepatic steatosis, insulin resistance and liver histology in NAFLD patients and normalizes serum aminotransferase level in NASH patients. ${ }^{41-44}$

\section{Diet control}

A recent meta-analysis has shown that caloric restriction is the most important goal for patients with NASH to improve hepatic steatosis. ${ }^{45}$ The general recommendations for the diet are individualized and patient is expected to achieve energy deficit of 500-1000 $\mathrm{kcal} /$ day depending on the patient's BMI. Saturated fat content should be reduced and total fat should constitute less than $30 \%$ of the total energy intake. Intake of refined sugars should be decreased with an increase in soluble fiber intake. ${ }^{27,46}$ One investigator found that drinks and foods high in fructose are associated with insulin resistance and the development of hepatic steatosis and thus should be avoided. ${ }^{47,48}$ Severe caloric restriction is not recommended as it can actually deteriorate the histological status in NAFLD patients and many a times is not sustainable. ${ }^{49}$

\section{Exercise}

The degree of hepatic fat reduction is proportional to the intensity of the lifestyle intervention and generally requires a body weight loss between 5 to $10 \% .^{50,51}$ Physical activities recommended for a NAFLD or NASH patient are 60 minutes/day for at least 3 days a week and progressively exercise should be increased to 5 days a week. ${ }^{47,48}$ An Indian study involving 60 NAFLD patients showed regular aerobic exercise for $30 \mathrm{~min} /$ day for at least 5 days a week improved insulin resistance resulting in improvement in ALT (decline from 84.8U/L to 41.3 U/L) and liver histology in NAFLD patients. ${ }^{44}$ Similar results were obtained from NASH patients (decline in ALT level from $70.5 \mathrm{U} / \mathrm{L}$ to $41.5 \mathrm{U} / \mathrm{L}$ ) also when they were subjected to aerobic exercise of $30 \mathrm{~min} /$ day for at least 5 days a week. ${ }^{52}$

However, there are some potential barriers to exercise that need to be carefully discussed and worked through with each patient. Fatigue is one of the most prevalent 
and pervasive symptoms in people with NASH which contribute to lack of confidence in NASH patients during exercise. ${ }^{52,53}$ There are no specific guidelines for an exercise program that have been developed for NASH patients. Many practitioners follow the American College of Sports Medicine's protocol for setting exercise goals and establishing a starting point. ${ }^{54}$ It should be kept in mind that exercise, even without weight loss, is associated with reduction in hepatic fat content and NAS score. Hence, exercise should be an integral part of lifestyle intervention, irrespective of patients' success in achieving the weight loss. Patients with LEAN NAFLD should also be advised exercise as these patients are shown to have high visceral adipose tissue despite normal BMI. ${ }^{44,55}$

\section{PHARMACOTHERAPY}

Pharmacotherapy is recommended for NASH patients (specially with significant fibrosis i.e. $\geq$ F2). ${ }^{3}$ Patients with diabetes, MetS, persistently increased ALT, high necro-inflammation even with less severe disease could also be considered for pharmacotherapy to prevent disease progression. ${ }^{15}$

Most of the current therapies are primarily directed towards improving the metabolic parameters which contribute to disease pathogenesis, such as weight loss, reducing insulin resistance and improving diabetic control. Pharmacological therapies for NAFLD and NASH usually include weight loss drugs like orlistat, insulin sensitizers such as metformin and thiazolidinediones, antioxidants such as Vitamin E and Ursodeoxycholic acid; and consideration of bariatric surgery for morbidly obese patients. However, with the increased understanding of pathogenesis of the disease, more effective and targeted therapies continue to emerge.

\section{Vitamin E}

Vitamin E is thought to decrease inflammation by acting as an antioxidant, thus decreasing oxidative cell damage. A number of open-label clinical trials have suggested the potential efficacy of vitamin E. This is best evidenced by PIVENS trial which showed a greater histological improvement in inflammation, but not in fibrosis, in nondiabetic patients taking vitamin E (800 mg/day) compared to those taking placebo and pioglitazone. ${ }^{56,57}$ The recent NAFLD guideline recommends Vitamin E as a first-line treatment for non-diabetic patients with only biopsy proven NASH and not recommended for NASH patients with diabetes due to lack of data on long-term safety and efficacy. ${ }^{38,58,59}$

\section{$U D C A$}

Ursodeoxycholic acid (UDCA), a secondary bile acid produced by intestinal bacteria as metabolic by product, has shown effective results in the treatment of nonsurgical removal of cholesterol gallstones and primary biliary cirrhosis. ${ }^{60}$ UDCA has anti-apoptic effects, lowers serum TNF-alfa concentration, decrease endoplasmic reticulum stress and improves hepatic insulin sensitivity. ${ }^{61-64}$ Based on these properties of UDCA, it is suggested to be effective in the treatment of NASH.

A pilot study by Laurin et al. wherein 24 NASH patients were treated with $13-15 \mathrm{mg} / \mathrm{kg} /$ day of UDCA for 12 months showed significant decrease in mean serum concentrations of AST (-8\%), ALT $(-30 \%)$ and gammaGT $(-45 \%)$ as well as a decrease in the histological grade of hepatic steatosis. ${ }^{65}$ A randomized controlled trial by Ratziu et al. enrolled 126 biopsy proven NASH patients randomized with either HD-UDCA $(28-35 \mathrm{mg} / \mathrm{kg} / \mathrm{d})$ or placebo for 1 year. The mean reduction in ALT, gammaGT levels and FibroTest ${ }^{\circledR}$ serum fibrosis marker $(p<0.001)$ was observed to be higher in UDCA group compared to placebo. ${ }^{66} \mathrm{An}$ Indian study with high dose UDCA ( $20 \mathrm{mg} / \mathrm{kg} /$ day) has demonstrated both safety and efficacy of UDCA in NASH patients. ${ }^{67}$ The safety and efficacy of UDCA in NAFLD is also supported by other studies including an Indian study. ${ }^{12,68} \mathrm{~A}$ meta-analysis by Xiang also supports use of UDCA as monotherapy and in combination with other drugs for NASH. ${ }^{69}$

\section{Thiazolidinediones}

Thiazolidinediones (TZDs) are known to enhance insulin sensitivity which prevents the activation of adiponectin thus impairing adipocyte storage of triglycerides. ${ }^{70}$ TZDs currently in clinical use include rosiglitazone and pioglitazone. Rosiglitazone has been shown to decrease aminotransferases and improve histological inflammation, but not fibrosis. ${ }^{71,72}$ In addition to rosiglitazone, pioglitazone has also been investigated for treatment of NASH. ${ }^{73-75}$ The durability of response of TZDs is questioned by Lutchman and collegues. They observed that after the discontinuation of TZDs, level of aminotransferase and homeostasis model assessment (HOMA) increases after 1 year and there are chances of recurrence of steatohepatitis. ${ }^{70}$ Also long term safety of glitazones is not established due to their association with cardiovascular diseases, congestive heart failure, bladder cancer, and bone loss. ${ }^{76,77}$

\section{Pentoxifylline}

Pentoxifylline (PTX) is a phosphodiesterase inhibitor that has been shown to inhibit TNF-alpha, a pro-inflammatory cytokine elevated in patients with NAFLD that may mediate insulin resistance and contribute to the progression of NASH. ${ }^{78}$ A number of studies have been done to evaluate the effects of PTX in NAFLD patients. 4 RCTs have shown that PTX $1200 \mathrm{mg}$ daily appears to improve histology via reduction in steatosis, inflammation, and even fibrosis. ${ }^{79-83}$ Further studies are needed to confirm these findings. 


\section{Metformin}

Metformin belongs to the class of medication called the biguanides and is a widely used oral medication for the treatment T2DM. Metformin is known for its effect on insulin resistance, and has also been investigated in patients with NASH. ${ }^{84}$ Many studies have shown an improvement in liver enzymes with metformin, however not all studies have reported the same result. A small randomized trial, the TONIC trial comparing metformin with vitamin $\mathrm{E}$ and placebo in children with NASH showed no significant change in histology. ${ }^{56}$ Thus, although metformin can be used for diabetic patients with $\mathrm{NASH}$, there are no evidence to support its efficacy solely from the standpoint of NASH.

\section{Statins}

Statins, 3-hydroxy-3-methylglutaryl-coenzyme A (HMG$\mathrm{CoA})$ reductase inhibitors, are a popular class of medication known for their use in reducing LDL and incidence of cardiovascular events. ${ }^{83}$ There are several studies of statins in patients with NASH suggesting improvement in liver enzymes, but no convincing histological data are available. Therefore, statins are not currently recommended to treat patients with NASH. $.8,85,86$

\section{Orlistat}

Orlistat drug is a reversible inhibitor of gastric and pancreatic lipase that inhibits enteric lipid absorption and hence has been promoted as a weight-loss aid. Orlistat in addition to lifestyle modification was evaluated as a potential therapy for NASH by Harrison and colleagues in an open-label trial comparing the combination of orlistat with vitamin $\mathrm{E}+\mathrm{a}$ multivitamin +1400 calorie/day diet vs. vitamin E+multivitamin+1400 calorie/day diet for 36 weeks. There was a slight improvement observed in NAFLD Activity Score (NAS) and fibrosis score in treatment group as compared to the control group. They determined that orlistat was safe and well tolerated, however orlistat alone was not found to add any further cardio-metabolic or histological changes over lifestyle modification alone. As data supporting the efficacy is lacking, orlistat is not highly recommended as a potential therapy for patients with NASH. ${ }^{87}$

\section{Novel drugs}

There are many new drugs under development for NASH. The two most advanced molecules are obeticholic acid and Elafibranor (both in Phase 3 clinical trials). Obeticholic acid has appeared to improve liver fibrosis 88,89 while elafibranor is supposed to improve glycemic and lipid profile in addition to improving fibrosis and inflammation. ${ }^{90,91}$ Liraglutide, a human long acting GLP1 analogue is reported to act directly on human hepatocytes in vitro, thus reducing steatohepatitis by decreasing de novo lipogenesis and increasing fatty acid oxidation..$^{92-94}$ Aramchol, which is a synthetic lipid molecule is shown in vitro to reduce the synthesis and increasing the beta oxidation of fatty acids and resulting in decreased hepatic accumulation of triglycerides and fatty acid esters. ${ }^{95}$ Cenicriviroc, another novel drug is demonstrated to have potent anti-inflammatory and antifibrotic activity. It is shown to decrease mean enhanced liver fibrosis (ELF) test index. ${ }^{96}$

\section{Bariatric surgery}

The effect of bariatric surgery for weight loss on NAFLD has been assessed with liver enzymes and histology. Several studies have shown improvement in aminotransferases and gamma-GT levels upon bariatric surgery. ${ }^{97,98}$ Recent studies investigating the surgical management of patients with morbid obesity and NASH found that weight loss following conventional nonmalabsorptive bariatric-metabolic procedures reduces steatosis and lobular inflammation, but may not have a consistent effect on liver fibrosis. Two meta-analyses evaluated the effect of bariatric surgery on liver histology in NAFLD patients. The one study by Mummadi et al. showed that steatosis, steatohepatitis and fibrosis appear to improve or resolve completely after bariatric procedure. ${ }^{99}$ However, rapid weight loss may produce a transient or prolonged increase in liver disease and therefore patients need careful monitoring to make sure weight loss occurs over time. ${ }^{100}$ Guidelines do not formally recommend bariatric surgery for treatment of NASH due to lack of strong published evidences.

\section{FOLLOW-UP STRATEGIES}

The optimal follow-up of patients with NAFLD is as yet undetermined. Risk of progression of the hepatic disease and the underlying metabolic conditions as well as the cost and workload for healthcare providers need to be considered. Monitoring should include routine biochemistry, assessment of comorbidities and noninvasive monitoring of fibrosis. NAFLD patients without worsening of metabolic risk factors should be monitored at 2 to 3 year intervals. Patients with NASH and/or fibrosis should be monitored annually and those with NASH cirrhosis at 6-month intervals. If indicated on a case-by-case basis, liver biopsy could be repeated after 5 years. $^{3}$

\section{DISCUSSION}

NAFLD is an umbrella term that encompasses the spectrum of liver disease from simple steatosis to NASH related cirrhosis and is increasingly recognized as major cause of liver related morbidity and mortality. ${ }^{96}$ The prevalence of NAFLD has risen rapidly in parallel with dramatic rise in obesity and diabetes. ${ }^{101,102}$ However, reallife practice has shown that awareness of NAFLD is low in the general population. Diagnosis of NAFLD is often missed due to underestimation of NAFLD being the cause of elevated liver enzymes. Patients with metabolic 
risk factors and raised liver enzymes must be screened for NAFLD, as specialists other than Hepatologists miss a high proportion of high risk NAFLD patients. Adequate work up is required in patients with metabolic syndrome. More attention should be paid to educate physicians/GPs on minimum clinical, anthropometric, laboratory evaluation in suspected NAFLD patients to facilitate early diagnosis and prevent complications. Collaborated work of Gastroenterologists, Hepatologists, Endocrinologists and Cardiologists is required for integrated management of NAFLD.

Lifestyle modification is universally considered as the first line therapy for patients with NAFLD and as per many guidelines; pharmacological therapy is reserved only for NASH patients. Current treatments are primarily directed towards improving the metabolic parameters which contribute to disease pathogenesis, such as weight loss and exercise, reducing insulin resistance, and improving diabetic control. ${ }^{97}$ The commonly used pharmacotherapeutic options include vitamin E, UDCA, pioglitazone and pentoxifylline. However, the list of potential drugs such as obeticholic acid, elafibranor, cenicriviroc, liraglutide and aramchol continues to expand considering targeted treatments as per the pathogenic mechanisms. ${ }^{61}$ Studies are demanded from India as ethnic difference may play a role in the occurrence and clinico-pathological profile of NAFLD patients. Further prospective studies will fill the various missing links associated with management of NAFLD in Indian patients in a more effective manner. ${ }^{103}$

\section{ACKNOWLEDGEMENTS}

Writing assistance was provided by Shalaka Marfatia and her team, pharm EDGE, supported through academic research funding from Abbott India Limited.

Funding: No funding sources

Conflict of interest: None declared

Ethical approval: Not required

\section{REFERENCES}

1. Duseja A. Nonalcoholic fatty liver disease in India a lot done, yet more required!. Indian J Gastroenterol. 2010;29:217-25.

2. Ekstedt M, Franzen L, Mathiesen U, Thorelius L, Holmqvist M, Bodemar $\mathrm{G}$ et al. Long-term follow-up of patients with NAFLD and elevated liver enzymes. Hepatol. 2006;44:865-73.

3. EASL-EASD-EASO Clinical practice guidelines for the management of non-alcoholic fatty liver disease. J Hepatol. 2016;64:1388-402.

4. Ayata G, Gordon F, Lewis W, Pomfret E, Pomposelli J, Jenkins $\mathrm{R}$ et al. Cryptogenic cirrhosis: clinicopathologic findings at and after liver transplantation. Hum Pathol. 2002;33:1098-104.

5. Shimada M, Hashimoto E, Taniai M, Hasegawa K, Okuda H, Hayashi N et al. Hepatocellular carcinoma in patients with non-alcoholic steatohepatitis. J Hepatol. 2002;37:154-60.

6. Ludwig J, Viggiano $\mathrm{T}$, McGill $\mathrm{D}, \mathrm{Oh} \mathrm{B}$. Nonalcoholic steatohepatitis: Mayo clinic experience with a hitherto unnamed disease. Mayo Clin Proc. 1980;55:434-8.

7. Sanyal A. American Gastroenterological Association. AGA technical review on nonalcoholic fatty liver disease. Gastroenterol. 2002;123:1705-25.

8. Neuschwander-Tetri B, Caldwell S. Nonalcoholic steatohepatitis: summary of an AASLD single topic conference. Hepatol. 2003;37:1202-19.

9. Das K, Das K, Mukherjee P, Ghosh A, Ghosh S, Mridha A et al. Nonobese population in a developing country has a high prevalence of nonalcoholic fatty liver and significant liver disease. Hepatol. 2010;51:1593-602.

10. Bellentani S, Saccoccio G, Masutti F, Croce L, Brandi G, Sasso F et al. Prevalence of and risk factors for hepatic steatosis in Northern Italy. Ann Intern Med. 2000;132:112-7.

11. Madan K, Batra Y, Gupta S, Chander B, Rajan K, Tewatia $\mathrm{M}$, et al. Non-alcoholic fatty liver disease may not be a severe disease at presentation among Asian Indians. World J Gastroenterol. 2006;12:34005.

12. Duseja A, Das A, Das R, Dhiman R, Chawla Y, Bhansali A et al. The clinicopathological profile of Indian patients with nonalcoholic fatty liver disease (NAFLD) is different from that in the west. Dig Dis Sci. 2007;52:2368-74.

13. Petersen K, Dufour S, Feng J, Befroy D, Dziura J, Man C, et al. Increased prevalence of insulin resistance and nonalcoholic fatty liver disease in Asian-Indian men. Proc Nat Acad Sci. 2006;103:18273-7.

14. Weiss R, Dziura J, Burgert T, Tamborlane W, Taksali S, Yeckel C et al. Obesity and the metabolic syndrome in children and adolescents. N Engl J Med. 2004;350:2362-74.

15. Nascimbeni F, Pais R, Bellentani S, Day C, Ratziu V, Loria $\mathrm{P}$ et al. From NAFLD in clinical practice to answers from guidelines. J Hepatol. 2013;59:859-71.

16. Bacon B, Farahvash M, Janney C, NeuschwanderTetri B. Nonalcoholic steatohepatitis: an expanded clinical entity. Gastroenterol. 1994;107:1103-9.

17. Angulo P. Nonalcoholic fatty liver disease. N Eng J Med. 2002;346(16):1221-31.

18. Tilg H, Diehl A. Cytokines in alcoholic and nonalcoholic steatohepatitis. $N$ Eng $J$ Med. 2000;343:1467-76.

19. Duseja A, Murlidharan R, Bhansali A, Sharma S, Das A, Das $R$ et al. Assessment of insulin resistance and effect of metformin in nonalcoholic steatohepatitis: a preliminary report. Indian J Gastroenterol. 2004;23:12-5.

20. Dhiman R, Duseja A. Nonalcoholic fatty liver disease. Medicine Update. 2005;94:469-75.

21. Day C, James O. Steatohepatitis: a tale of two "hits"?. Gastroenterol. 1998;114:842-5. 
22. Dowman J, Tomlinson J, Newsome P. Pathogenesis of non-alcoholic fatty liver disease. Q J Med. 2010;103:71-83.

23. Singh S, Panigrahi M. Guidelines for Assessment and Management of Nonalcoholic Fatty Liver Disease in Indians, Chapter 55. Available at http://www.apiindia.org/medicine_update_2013/chap 55.pdf. Accessed on 14th January 2017.

24. Byrne C, Targher G. EASL-EASD-EASO Clinical Practice Guidelines for the management of nonalcoholic fatty liver disease: is universal screening appropriate?. Diabetologia 2016;59:1141-4.

25. Duseja A, Singh S, Saraswat V, Acharya S, Chawla Y, Chowdhury $S$ et al. Non-alcoholic fatty liver disease and metabolic syndrome-position paper of the Indian national association for the study of the liver, endocrine society of India, Indian college of cardiology and Indian society of gastroenterology. J Clin Exp Hepatol. 2015;5:51-68.

26. Loguercio C, Tiso A, Cotticelli G, Blanco C, Arpino $G$, Laringe $M$ et al. Management of chronic liver disease by general practitioners in southern Italy: unmet educational needs. Dig Liver Dis. 2011;43:736-41.

27. Farrell G, Chitturi S, Lau G, Sollano J, Asia Working Party on NAFLD. Guidelines for the assessment and management of Non-Alcoholic Fatty Liver Disease in the Asia-Pacific Region. J Gastroenterol Hepatol. 2007;22:775-7.

28. WHO Expert Consultation. Appropriate body-mass index for Asian populations and its implications for policy and intervention strategies. Lancet. 2004;363:157-63

29. Grattagliano I, D’Ambrosio G, Palmieri V, Moschetta A, Palasciano G, Portincasa P. Steatostop Project' Group. Improving nonalcoholic gatty liver disease management by general practioners: a critical evaluation and impact of of an educational training program. J Gastrointest Liver Dis. 2008;17:389-94.

30. Falck-Ytter Y, Younossi Z, Marchesini G, McCullough A. Clinical features and natural history of nonalcoholic steatosis syndromes. Semin Liver Dis. 2001;21:17-26.

31. Mishra P, Younossi Z. Abdominal ultrasound for diagnosis of nonalcoholic fatty liver disease (NAFLD). Am J Gastroenterol. 2007;102:2716-7.

32. Strauss S, Gavish E, Gottlieb P, Katsnelson L. Interobserver and intraobserver variability in the sonographic assessment of fatty liver. AJR Am J Roentgenol. 2007;189:W320-3.

33. Davidson L, Kuk J, Church T, Ross R. Protocol for measurement of liver fat by computed tomography. $\mathrm{J}$ Appl Physiol. 2006;100:864-8.

34. Szczepaniak L, Nurenberg P, Leonard D, Browning J, Reingold J, Grundy S et al. Magnetic resonance spectroscopy to measure hepatic triglyceride content: prevalence of hepatic steatosis in the general population. Am J Physiol Endocrinol Metab. 2005;288:E462-8.
35. Wong V, Chu W, Wong G, Chan R, Chim A, Ong A, et al. Prevalence of non-alcoholic fatty liver disease and advanced fibrosis in Hong Kong Chinese: a population study using proton-magnetic resonance spectroscopy and transient elastography. Gut. 2016;61:409-15.

36. Ratziu V, Cadranel J, Serfaty L, Denis J, Renou C, Delassalle P, et al. A survey of patterns of practice and perception of NAFLD in a large sample of practicing gatsroenterologists in France. J Hepatol. 2012;57:376-83.

37. Arora A, Sharma P. Non-invasive diagnosis of fibrosis in non-alcoholic fatty liver disease. J Clin Exp Hepatol. 2012;2:145-55.

38. Chalasani N, Younossi Z, Lavine J, Diehl A, Brunt E, Cusi K, et al. The diagnosis and management of nonalcoholic fatty liver disease: practice guideline by the American association for the study of liver diseases, American college of gastroenterology, and the American gastroenterological association. Hepatol. 2012;55:2005-23.

39. Bergqvist C, Skoien R, Horsfall L, Clouston A, Jonsson J, Powell E. Awareness and opinions of nonalcoholic fatty liver disease by hospital specialists. Intern Med J. 2013;43:247-53.

40. Zelber-Sagi S, Ratziu V, Oren R. Nutrition and physical activity in NAFLD: an overview of the epidemiological evidence. World J Gastroenterol. 2011;17:3377-89.

41. Sreenivasa Baba C, Alexander G, Kalyani B, Pandey R, Rastogi S, Pandey A, et al. Effect of exercise and dietary modification on serum aminotransferase levels in patients with non-alcoholic steatohepatitis. J Gastroenterol Hepatol. 2006;21:191-8.

42. Ueno T, Sugawara H, Sujaku K, Hashimoto O, Tsuji $\mathrm{R}$, Tamaki S, et al. Therapeutic effects of restricted diet and exercise in obese patients with fatty liver. $\mathbf{J}$ Hepatol. 1997;27:103-7.

43. Suzuki A, Lindor K, St Saver J, Lymp J, Mendes F, Muto A, et al. Effect of changes on body weight and lifestyle in non-alcoholic fatty liver disease. J Hepatolo. 2005;43:1060-6.

44. Bhat G, Baba C, Pandey A, Kumari N, Choudhari G. Life style modification improves insulin resistance and liver histology in patients with non-alcoholic fatty liver disease. World J Hepatol. 2012;4:209-17.

45. Musso G, Bo S, Cassader M, Michieli F, Gambino R. Impact of sterol regulatory element-binding factor-1c polymorphism on incidence of nonalcoholic fatty liver disease and on the severity of liver disease and of glucose and lipid dysmetabolism. Am J Clin Nutr. 2013;28:895-906.

46. Amarpurkar D. Approach to NAFLD in India in NonAlcoholic Fatty Liver Disease. Khanna S (Ed). ECAB Clinical update Gatsroenterology Hepatology. New Delhi: Elsevier 2010;57-75.

47. Simopoulos A. Dietary omega-3 fatty acid deficiency and high fructose intake in the development of metabolic syndrome, brain metabolic abnormalities, 
and non-alcopholic fatty liver disease. Nutrients. 2013;5:2901-23.

48. Capanni M, Calella F, Biagini M, Genise S, Raimondi L, Bedogni G, et al. Prologed n-3 polyunsaturated fatty acid supplementation ameliorates hepatic steatosis in patients with nonalcoholic fatty liver disease: a pilot study. Aliment Pharmacol Ther. 2006;23:1143-51.

49. Nair S. Nonalcoholic fatty liver disease from the perspective of an internist. The Ochsner J. 2002;4:927.

50. Tamura Y, Tanaka Y, Sato F, Choi J, Watada H, Niwa M, et al. Effects of diet and exercise on muscle and liver intracellular lipid contents and insulin sensitivity in type 2 diabetic patients. J Clin Endocrinol Metab. 2005;90:3191-6.

51. Kantartzis K, Thamer C, Peter A, Machann J, Schick F, Schraml C et al. High cardiorespiratory fitness is an independent predictor of the reduction in liver fat during a lifestyle intervention in non-alcoholic fatty liver disease. Gut. 2009;21:1281-8.

52. Newton JL. Systematic symptoms in non-alcoholic fatty liver disease. Dig Dis. 2010;28:214-9.

53. Price JK, Srivastava R, Bai C, Diao G, Gerber LH, Younossi ZM. Comparision of activity level among patients with chronic liver disease. Disabil Rehabil. 2013;35:907-12.

54. Gerber CE, Blissmer B, Deschenes MR, Franklin BA, Lamonte MJ, Lee IM et al. Quantity and quality of exercise for developing and maintaining cardiorespiratory, muscoskeletal, and neuromotor fitness in apparently healthy adults: guidance for prescribing exercise. Med Sci Sports Exerc. 2011;43:1334-59.

55. Foxx-Orenstein AE. New and emerging therapies for the treatment of irritable bowel syndrome: an update for gastroenterologists. Therap Adv Gastroenterol. 2016;9:394-407.

56. Lavine JE, Schwimmer JB, Van Natta ML, et al. Effect of vitamin $\mathrm{E}$ or metformin for treatment of nonalcoholic fatty liver disease in children and adolescents: the TONIC randomized controlled trial. JAMA. 2011;305:1659-68.

57. Sanyal AJ, Chalasani N, Kowdley KV, Mc Cullough A, Diehl AM, Bass NM, et al. Pioglitazone, Vitamin E, or placebo for nonalcoholic steatohepatitis. N Engl J Med. 2010;362:1675-85.

58. Pathil A, Mueller J, Warth A, Chamulitrat W, Stremmel W. Ursodeoxycholyl lysophosphatidylethanolamide improves steatosis and inflammation in murine models of nonalcoholic fatty liver disease. Hepatol. 2012;55:1369-77.

59. Musso G, Anty R, Petta S. Antioxidant therapy and drugs interfering with lipid metabolism: could they be effective in NAFLD patients? Curr Pharm Des. 2013;19:5297-313.

60. Ishizaki K, Imada T, Tsurufuji M. Hepatoprotective bile acid 'Ursodeoxycholic acid (UDCA)' Property and difference as bile acids. Hepatol Res. 2005;33:174-7.
61. Kotb MA. Molecular mechanisms of Ursodeoxycholic acid toxicity and side effects: Ursodeoxycholic acid freezes regeneration and induces hibernation mode. Int $\mathrm{J}$ Mol Sci. 2012;13:8882-914.

62. Feldstein AE, Canbay A, Angulo P, Taniai M, Burgart LJ, Lindor KD, et al. Hepatocyte apoptosis and fas expression are prominent features of human nonalcoholic steatohepatitis. Gastroenterology 2003; 125:437-43

63. Amaral JD, Viana RJ, Ramalho RM, Steer C, Rodrigues C. Bile acids: regulation of apoptosis by ursodeoxycholic acid. J Lipid Res. 2009;50:1721-34.

64. Neuman M, Angulo P, Malkiewicz I, Jorgensen R, Shear N, Dickson ER et al. Tumor necrosis factoralpha and transforming growth factor-beta reflect severity of liver damage in primary biliary cirrhosis. $\mathbf{J}$ Gastroenterol Hepatol. 2002;17:196-202.

65. Laurin J, Lindor KD, Crippin JS, Gossard A, Gores $\mathrm{G}$, Ludwig J, et al.Ursodeoxycholic acid or clofibrate in the treatment of non-alcohol-induced steatohepatitis: a pilot study. Hepatol. 1996;23:14647.

66. Ratziu V, de Ledinghen V, Oberti F, Mathurin P, Wartelle-Bladou C, Renou C, et al. A randomized controlled trial of high-dose Ursodeoxycholic acid for non-alcoholic steatohepatitis. J Hepatol. 2011;54:1011-9.

67. Singh SP, Das HS, Panda C. A pilot study of high dose Ursodeoxycholic acid [UDCA] in the treatment of nonalcoholic steatohepatitis [NASH]. Indian $\mathbf{J}$ Gastroenterol. 2007;26:A90.

68. Troisi G, Crisciotti F, Gianturco V, D'Ottavio E, Lo lacono $\mathrm{C}$, Farmosa $\mathrm{V}$, et al . The treatment with ursodeoxycholic acid in elderly patients affected by NAFLD and metabolic syndrome: a case-control study. Clin Ter. 2013;164:203-7.

69. Xiang Z, Chen Y, Ma KF, Ye YF, Zheng L, Yang $\mathrm{YD}$, et al. The role of ursodeoxycholic acid in nonalcoholic steatohepatitis: a systematic review. BMC Gastroenterol. 2013;13:140.

70. Yki-Jarvinen H. Thiazolidinediones. New Engl J Med. 2004;351:1106-18.

71. Neuschwander-Tetri BA, Brunt EM, Weheier KR, Oliver D, Bacon BR. Improved nonalcoholic steatohepatitis after 48 weeks of treatment with PPAR-gamma ligand rosiglitazone. Hepatol. 2003;38:1008-17.

72. Ratziu V, Giral P, Jacqueminet S, Charlotte F, Hartemann-Heurtier A, Serfaty L et al. Rosiglitazone for nonalcoholic steatohepatitis: one -year results of the randomized placebo controlled fatty liver improvement with rosiglitazone therapy (FLIRT) Trial. Gastroenterol. 2008;135:100-10.

73. Belfort R, Harrison SA, Brown K, Darland C, Finch $\mathbf{J}$, Hardies $\mathbf{J}$ et al. A placebo- controlled trial of pioglitazone in subjects with nonalcoholic steatohepatitis. N Engl J Med. 2006;355:2297-307.

74. Aithal GP, Thomas JA, Kaye VP, Lawson A, Ryder SD, Spendlove I et al. Randomized, placebo- 
controlled trial of pioglitazone in nondiabetic subjects with nonalcoholic steatohepatitis. Gastroenterol. 2008;135:1176-84.

75. Chalasani NP, Sanyal AJ, Kowdley KV, Robuck PR, Hoofnagle J, Kleiner DE et al. Pioglitazone versus vitamin $\mathrm{E}$ versus placebo for the treatment of nondiabetic patients with non-alcoholic steatohepatitis: PIVENS trial design. Contemp Clin. Trials 2009;30:88-96.

76. Dormandy JA, Charbonnel B, Eckland DJ, Erdmann E, Massi-Benedetti M, Moules IK et al. Secondary prevention of macrovascular events in patients with type 2 diabetes in the PROactive study (PROspective pioglitazone Clinical trial in Macrovascular events): a randomized controlled trial. Lancet. 2005;366:127989

77. Azoulay L, Yin H, Filion KB, Assayag J, Majdan A, Pollark MN et al. the use of pioglitazone and the risk of bladder cancer in people with type 2 diabetes: nested case-control study. BMJ. 2012;344:e3645.

78. Duman DG, Ozdemir F, Birben E, Keskin O, Ekşioğlu-Demiralp E, Celikel $\mathrm{C}$ et al. Effects of pentoxifylline on TNF-alpha production by peripheral blood mononuclear cells in patients with nonalcoholic steatohepatitis. Dig Dis Sci. 2007;52:2520-4.

79. Buranawati W, Thoun-U-Thaisri P, Pramoolsinsup C, Wisedopas N, Atamasirikul K, Udomsubpayakul U et al. Pentoxifylline for treatment of nonalcoholic fatty liver disease (NAFLD): a randomized, placebocontrolled study. Thai J Gastroenterol 2007;8:57-63.

80. Lee YM, Sutedja DS, Wai CT, Dan YY, Aung MO, Zhou L et al. A randomized controlled pilot study of pentoxifylline in patients with non-alcoholic steatohepatitis (NASH). Hepatol Int. 2008;2:196-201.

81. Van Wagner LB, Koppe SW, Brunt EM, Gottstein J, Gardikiotes K, Green RM et al. Pentoxifylline for the treatment of non-alcoholic steatohepatitis: a randomized controlled trial. Ann Hepatol. 2011;10:277-86.

82. Zein CO, Yerian LM, Gogate P, Lopez R, Kirwan JP, Feldstein $\mathrm{AE}$ et al. Pentoxifylline improves nonalcoholic steatohepatitis: a randomized placebocontrolled trial. Hepatol. 2011;54:1610-9.

83. Roglans N, Sanguino E, Peris C, Alegret M, Vázquez $\mathrm{M}$, Adzet $\mathrm{T}$ et al. Atorvastatin treatment induced peroxisome proliferator-activated receptor alpha expression and decreased plasma nonesterified fatty acids and liver triglyceride in fructose-fed rats. J Pharmacol Exp Ther. 2002;302:232-9.

84. Viollet B, Guigas B, Sanz Garcia N, Leclerc J, Foretz M, Andreelli F. Cellular and molecular mechanisms of metformin: an overview. Clin Sci. 2012;122:25370 .

85. Chalasani N, Younossi Z, Lavine JE, Diehl AM, Brunt EM, Cusi $\mathrm{K}$, et al. The diagnosis and management of non-alcoholic fatty liver disease: practice guideline by the American gastroenterological association, American association for the study of liver diseases, and American college of gastroenterology. Gastroenterol. 2012;142:1592609.

86. Chalasani N, Younossi Z, Lavine JE, Diehl AM, Brunt EM, Cusi $\mathrm{K}$ et al. The diagnosis and management of non-alcoholic fatty liver disease: practice guideline by the American association for the study of liver diseases, American college of gastroenterology, and the American gastroenterological association. Am J Gastroenterol. 2012;107:811-26.

87. Harrison SA, Fecht W, Brunt EM, NeuschwanderTetri BA. Orlistat for overweight subjects with nonalcoholic steatohepatitis: a randomized, prospective trial. Hepatol. 2009;49:80-6.

88. Adorini L, Pruzanski M, Shapiro D. Farnesoid X receptor targeting to treat nonalcoholic steatohepatitis. Drug Discov Today. 2012;17:988-97.

89. Zhang Y, Kast-Woelbern HR, Edwards PA. Natural structural variants of the nuclear receptor farnesoid $\mathrm{X}$ receptor affect transcriptional activation. J Biol Chem. 2003;278:104-10.

90. Cariou B, Staels B. GFT505 for the treatment of nonalcoholic steatohepatitis and type 2 diabetes. Expert Opin Investig Drugs. 2014;23:1441-8.

91. Cariou B, Zair Y, Staels B, Bruckert E. Effects of the new dual PPAR alpha/delta agonist GFT505 on lipid and glucose homeostasis in abdominally obese patients with combined dyslipidemia or impaired glucose metabolism. Diab Care. 2011;34:2008-14.

92. Ding X, Saxena NK, Lin S, Gupta NA, Anania FA. Exendin-4,a glucagon-like protein-1 (GLP-1) receptor agonist, re-verses hepatic steatosis in ob/ob mice. Hepatol. 2006;43:173-81.

93. Ben-Shlomo S, Zvibel I, Shnell M, Shlomai A, Chepurko E, Halpern Z et al. Glucagon-like peptide-1 reduces hepatic lipogenesis via activation of AMPactivated protein kinase. J Hepatol. 2011;54:1214-23.

94. Gupta NA, Mells J, Dunham RM, Grakoui A, Handy J, Saxena NK et al. Glucagon-like peptide-1 receptor is present on human hepatocytes and has a direct role in decreasing hepatic steatosis in vitro by modulating elements of the insulin signaling pathway. Hepatol. 2010;51:1584-92.

95. Dobrzyn A, Dobrzyn P, Lee SH, Miyazaki M, Cohen P, Asilmaz E et al. Stearoyl-CoA desaturase-1 deficien-cy reduces ceramide synthesis by downregulating serine palmitoyltransferase and increasing beta-oxidation in skeletal muscle. Am J Physiol Endocrinol Metab. 2005;288:E599-E607.

96. Younossi ZM, Reyes MJ, Mishra A, Mehta R, Henry L. Systematic review with meta-analysis: nonalcoholic steatohepatitis - a case for personalised treatment based on pathogenic targets. Aliment Pharmacol Ther. 2014;39:3-14.

97. Stephen S, Baranova A, Younossi ZM. Nonalcoholic fatty liver disease and bariatric surgery. Expert Rev Gastroenterol Hepatol. 2012;6:163-71.

98. Tai CM, Huang CK, Hwang JC. Improvement of nonalcoholic fatty liver disease after bariatric surgery 
in morbidly obese Chinese patients. Obes Surg. 2012;22:1016-21.

99. Mummadi RR, Kasturi KS, Chennareddygair S, Sood GK. Effect of bariatric surgery on nonalcoholic fatty liver disease: systematic review and meta-analysis. Clinical Gastroenterol Hepatol. 2008;6:1396-402.

100.Chavez-Tapia NC, Tellez-Avila FI, BarrientoseGutierrez T, Mendez-Sanchez N, Lizardi-Cervera J, Uribe M. Bariatric surgery for non-alcoholic steatohepatitis in obese patients. Cochrane Database Syst Rev. 2010;20:CD007340.

101.Ratziu V, Bellentani S, Cortez-Pinto H, Day C, Marchesini G. A position statement on
NAFLD/NASH based on the EASL 2009 special conference. J Hepatol. 2010;53:372-84.

102.Misra A, Misra R. Asian Indians and insulin resistance syndrome: global perspective. Metab Syndr Relat Disord. 2003;1:277-83.

103. Corrado RL, Torres DM, Harrison SA. Review of treatment options for nonalcoholic fatty liver disease. Med Clin North Am. 2014;98:55-72.

Cite this article as: Choudhuri G, Gupta V.

Evidence based literature review of clinical management of non-alcoholic fatty liver disease in real world settings. Int J Basic Clin Pharmacol 2017;6:1020-30. 